\title{
Borderline personality disorder and lived time ${ }^{\text {¿ }}$
}

\author{
Trouble de personnalité borderline et temps vécu
}

\author{
Fabian Lo Monte (Psychologist), Jérôme Englebert (Lecturer)*
}

\author{
Department of Psychology, université de Liège, quartier Agora, place des Orateurs 1 (Bât B33), 4000 Liège, Belgium
}

\begin{abstract}
Objectives. - Starting from the semiological heterogeneousness of borderline patients, we try to understand the everyday life of such subjects, and to determine the psychopathological structure of Borderline Personality Disorder.

Method. - This article's principal focus is lived time. We explore diverse meanings of the notions of immediacy and instantaneity, considered as key components of borderline patients' lived time. We also consider other existential concepts from phenomenological psychopathology, such as space, emotion, identity, and the body.

Results. - The fragmented self hypothesis (Fuchs, 2007) clarifies the way in which borderline patients relate to the main psychic functions, and reveals a being-in-the-world in excess of the spatio-temporal situation. In addition, Kimura's notion of the intra festum (1992), closely correlated to the notions of instantaneity and immediacy, is put into a fruitful dialogue with the notions of the fragmented self and of the exceeding of the spatio-temporal situation.

Discussion. - The growing prevalence of BPD, along with the quality of the experiences narrated by borderline patients, allow us to suggest a link between a borderline being-in-the-world and our society's incessant technological advances, which contain the possibility of modifying the coordinates of space and time.

Conclusion. - The different concepts explored in this article ultimately appear to link back up with the notions of instantaneity and immediacy. These two terms, closely related but calling upon different points of view, are closely connected with a certain hypo-reflexivity, whose expression differs according to whether one situates it in the "normal" or the in the pathological. Hypo-reflexivity appears in the context of a social world characterized by the constant need for hyper-flexibility (which notion brings us back to immediacy
\end{abstract}

\footnotetext{
is Any reference to this article must mention: Lo Monte F, Englebert J. Trouble de personnalité borderline et temps vécu. Evol psychiatr 2018;83(4):(pages) (for the paper version) or URL [date of visit] (for the online version).

* Corresponding author.

E-mail address: jerome.englebert@uliege.be (J. Englebert).
} 
and instantaneity). Thus, the borderline experience overlaps with our postmodern lifestyle, which in turn reveals the potentially adaptive dimensions of this personality disorder.

(C) 2018 Elsevier Masson SAS. All rights reserved.

Keywords: Borderline personality disorder; Psychopathology; Lived time; Phenomenology; Mediation

\section{Résumé}

Objectifs. - Partant du constat de l'importante hétérogénéité sémiologique présentée par les sujets étatlimite, cette contribution tente de faire émerger une charpente psychopathologique du trouble de personnalité borderline afin de mieux comprendre le vécu des patients affectés par ce dernier.

Méthode. - Le temps vécu est l'angle d'attaque principal choisi dans cet article. La réflexion s'articule autour des notions d'instantanéité et d'immédiateté et en explore les différentes significations. Les autres coordonnées existentielles communément investiguées en psychopathologie phénoménologique, comme les rapports à l'espace, à l'identité, au vécu émotionnel ou au corps sont également étudiées.

Résultats. - La fragmentation temporelle du soi (Fuchs, 2007) que nous décrivons peut être considérée comme organisant le rapport aux principales fonctions psychiques chez les patients borderline, et révèle un être-aumonde tendant vers un dépassement de la situation spatio-temporelle. En outre, la façon de vivre le temps que Kimura (1992) nomme intra festum, qui est étroitement liée aux notions d'instantanéité et d'immédiateté telles que nous les développons, semble se combiner de façon fructueuse avec la fragmentation temporelle du soi et le dépassement de la situation.

Discussion. - La combinaison entre l'augmentation de la prévalence du trouble et la qualité des expériences rapportées par les patients permet de suggérer un lien entre l'être-au-monde borderline et l'évolution de notre société, faite d'avancées technologiques incessantes à-mêmes de permettre une modification des coordonnées spatio-temporelles.

Conclusion. - Les différentes conceptions exposées dans cet article semblent finalement se rejoindre autour des notions d'instantanéité et d'immédiateté. Ces deux termes, très proches, mais convoquant des points de vue différents, semblent entretenir un lien étroit avec une certaine hypo-réflexivité. Celle-ci s'exprime à des degrés divers selon que l'on se situe dans la «normalité » ou la pathologie, et peut être comprise en lien à un contexte social caractérisé par une nécessité d'hyper-flexibilité quotidienne (qui nous ramène à nouveau à l'immédiateté et à l'instantanéité). Ainsi, plusieurs points de l'expérience borderline peuvent être rapprochés du mode de vie postmoderne, et cela révèle les dimensions potentiellement adaptatives de ce trouble de la personnalité.

(C) 2018 Elsevier Masson SAS. Tous droits réservés.

Mots clés : Trouble de la personnalité borderline ; Psychopathologie ; Phénoménologie ; Temps vécu ; Médiation

\section{Introduction}

Borderline personality disorder, as defined by the latest versions of the DSM ( - IV and -5 ) $[1,2]$, is characterized by its considerable semiological heterogeneousness. The difficulties these patients face range from interpersonal struggles (with, notably, the fear of abandonment and extreme oscillations in their perceptions of others) to questions about identity; self-harming behaviors; a variety of substance use and abuse patterns; addictive behaviors; mood swings and excessive emotionality; a certain impulsiveness and a tendency to impatience and to the search for immediate satisfaction; or, finally, transitory pseudo-psychotic symptoms such as persecutory delusions. 
The description and comparative analysis of these different clinical signs proposed by various reference works [3-5] gives the impression of an accumulation of largely unrelated manifestations whose underlying coherence is enigmatic at best. Here, phenomenology can be a great help in identifying the "psychopathological organizer" of these diverse symptoms. The phenomenological approach, which consists in elucidating the structural dimension of a psychopathological entity - in the present case, the borderline personality -, provides us with a more integrated vision of this disorder $[6,7]$.

The present article aims to participate in this quest for understanding, by focusing on the temporal and subjective experiences (i.e. "lived time") of people presenting borderline personality disorder. Our work examines some of phenomenology's pioneering propositions ${ }^{1}$ [8-14] and proposes a dynamic synthesis. In this article, we will isolate and focus on the temporal variable, even if this approach is somewhat artificial, and even if other, cardinal dimensions such as the relation to space, to the body, or to the emotions are also central to the borderline experience. (These other aspects will be, evidently, evoked here.).

\section{Immediacy, lack of mediation, and the emotional experience}

For Kimura [8], various anomalies in the experience of time can be found in different mental pathologies and in different personality types. We should begin by pointing out that patients themselves aren't necessarily conscious of this (lived time is different than the consciousness of time, in which time becomes the content of the experience of consciousness), but that problematic experiences of time manifest themselves in patients' ways of thinking, of hoping, of living in the present, of remembering the past, and of projecting themselves into the future. In this case, Kimura's central thesis is that borderline patients' way of experiencing time reflects a mode of existence governed by immediacy. Regarding this acute experience of time, we can also refer to Muscelli and Stanghellini [10,11], who build on Kimura's hypothesis and evoke the notion of instantaneity.

In this case of the present article, these terms should not be understood only according to their habitual meanings, that is, those of brevity or rapidity. Instead, these terms also refer to the fact that borderline patients' psychic existence is characterized by an absence of mediation (inasmuch as, given the cultural and linguistic milieu in which each human being is born and develops, and given the relatively uninterrupted character of the human stream of consciousness, this mediation can be truly said to be totally absent). Borderline patients can present difficulties in representing events for themselves, in reflecting upon them, or, in Kimura's words [8], in transforming the events and emotions experienced in the present - im-mediately and noetically - into noematic or reflectively conscious contents. This is what leads phenomenologists to say that borderline patients live an ahistorical (or cyclical) temporality, that they experience time as an immediate present in which past and future are never considered as such [8]. Indeed, if experiences can't be represented, conceptualized, or reflected upon, it becomes difficult for the person to create her own narrative identity [9]. For the borderline person, this "existential framework" that integrates past events (or, rather, the representations that the person should have of past events) in order to determine projections for the future (or, more precisely, representations of future events that should be present in the form of hopes, motivations, intentions, projects, and other promises) is

\footnotetext{
${ }^{1}$ See also: Englebert J, Follet V. "Du définitif au provisoire...": Psychopathologie et tatouage. In: Krtolica I, Feneuil A (Eds.), L'expérience de l'éternité. Paris: Hermann; 2018. In press.
} 
deficient, which makes the attribution of personal meaning to events less effective and which can strip these events of their existential significance. The borderline patient is "caught up" in each new moment as it arrives - or, as may be the case, in a single present moment without temporal limits, without articulation -, since the functions of thought and of language that allow one to experience and assimilate events through higher level cognitions and elaborations seem to be inefficient and, above all, overwhelmed by the impulses of the moment.

Just as "immediacy" should not be reduced to its commonly accepted meaning, the present or the presence in question should not be solely understood as "the now that punctuates the axis of time, nor as a virtual point that can be represented as the border of the future and of the past without being experienced as such" ([8], p. 111). Instead, these notions should be understood as a tendency to be absorbed by the immediate, by that which "pre-dates the verbal-discernment determination" ([8], p. 148), and which allows the borderline patient to tear himself away from a feeling of emptiness; from a dysphoric mood; or from the feelings of urgency, anxiety, and irritability that accompany these states. This tendency is similar to the one that prevails during a party, where the attraction to breaking away from the daily routine (a daily routine that, for the borderline patient, would amount to a feeling of emptiness and a depressive mood) is stronger than anything else - and carries with it the risk of losing oneself. This propensity to "fill the void of existence through moments of ecstasy, to act out the principles of life and death" ([8], p. 115) - in other words, concretely, to forget oneself in explosions of anger, in episodes of substance abuse and other acts of self-harm - leads Kimura to refer to the borderline patient's "intra festum" (literally, "during the celebration") mode of existence. Indeed, this reference to celebration, to ecstasy, to this sort of "chaotic immediacy" ([8], p. 148) makes sense if we remind ourselves of elements that occur regularly in a borderline patient's daily life: addiction (alcohol, drugs, gambling); disordered eating (particularly binge eating); compulsive spending; sexual promiscuity; and/or violence (directed towards oneself or towards others). As mentioned above, Kimura goes so far as to describe an experience where "the principles of life and death are neither antagonistic nor mutually exclusive" ([8], p. 148).

From another disciplinary standpoint, Duvignaud's study Le don du rien [15] allows us to link an anthropological understanding of festivity to the borderline person's ambivalent and often destructive relational dynamic. The party - which, contrary to the borderline experience, is temporarily circumscribed - can be understood as a paradoxical relational act built upon inutility and nothingness. Duvignaud's position - that the "gratuitous" nature of the party is essential to society's functioning - is entirely reasonable; however, an existence that is exclusively founded on this dimension will inevitably pose a problem in terms of the subject's identity and relationships.

While the borderline patient strives to create a permanent "party world", this does not mean that she lives in a state of absolute bliss. Instead, the immediate present of such patients alternates between dysphoric moods and moments of anger or shame (often motivated by the sense of urgency provoked by dysphoria). Stanghellini and Rosfort [12] evoke a "dysphoria-anger complex" in which the dysphoric mood is conceived of as a centrifugal force that "fragments the borderline person's representations of herself and others, thus contributing to her painful experience of incoherence and inner emptiness, her threatening feeling of uncertainty and inauthenticity in interpersonal relationships, and her excruciating sense of insignificance, futility, and the inanity of life" ([12], p. 262), and in which anger is a centripetal force that "restores the cohesion of the self, determines a clear-cut, unambiguous image of the other, and dissipates all doubts and sentiments of absurdity at the cost of acute, though transitory, persecutory delusions" ([12], p. 262). The borderline subject must somehow get through life without the felt consistency that comes from the direct and implicit experience of an integrated past and of a truly anticipated 
future. He must do without the "force" that would allow him to stay the course and to forge an identity thanks to "second-order volitions" [12,16], that is, englobing, overarching, and durable volitions that allow a person to seize those opportunities for autonomy and self-determination that are available to every human being - instead of being guided by his impulses and other spontaneous outbursts (which are, in substance, the "first-order desires" mentioned by Frankfurt $[12,16])$.

\section{Postmodernity and the fragmentation of the self}

The modifications to the way in which consistency, commitment, and responsibility are experienced (both implicitly and explicitly) suggest profound existential difficulties, both for the borderline patient as well as, more broadly, within our postmodern society. The process of forging an identity is particularly difficult, and subjects' capacities for reflexivity ${ }^{2}$ and self-determination are compromised. In this article, our primary focus is on the temporal dimension of the postmodern experience, which Fuchs discerns in the "acceleration of momentary events, (the) mobility of work life, (the) futility of communication" ([9], p. 385). The acceleration of time (and of the pace of life) - which compels the postmodern subject to experience everything that this life has to offer - brings about a feeling that Muscelli and Stanghellini call fragmentation [10]. Daily life in postmodernity is characterized by the propensity to satisfy an immediate desire at the expense of building for the future; the increasing brevity and instantaneousness of events; ever-increasing mobility; and the ubiquitous and impersonal character of communication. In the context of global capitalism fueled by technological advances, the phenomena of totalized commodification and hyper-consumption encroach upon the Other; on our interpersonal relationships; and, ultimately, on our lives [19]. This allows us to suggest a link between the increasing prevalence of borderline personality disorder and our society's evolution.

Following Fuchs, we can speak of a temporal fragmentation of the self, of a fragmentation of identity, and of a fragmentation of the narrative identity [9]. This temporary fragmentation of the self calls to mind a particular form of intolerance for the ambiguity and uncertainty that are part of any long-term interpersonal relationship, and, especially, a rejection of the dimensions of commitment, responsibility, and guilt that these relationships tend to produce. Rather than consenting to a minimum of the repression that personal growth requires, rather than eliminating (voluntarily but also involuntarily) certain undesirable compulsions while fostering others in order to live according to a code that could define her values and her identity, the borderline patient has a tendency to not choose; she adapts, instead, by cleaving her identity. In so doing, she deprives this identity of its normal temporal dimension, by eliminating past and future in order to avoid object permanence, bonds, commitment, responsibility, and guilt - all of which participate in anchoring subjects in the long-term, at least if we refer to the dominant social and relational system that preceded the gradual advent of postmodernity. In sum, we can suggest that this type of patient adopts a resolutely "postmodern" lifestyle, in which the subject is unmoored from the usual coordinates of time and space (as we will see later on).

\footnotetext{
${ }^{2}$ In the context of this article, the concept of reflexivity is borrowed from the works of the American phenomenologist Louis Sass [17,18]. Reflexivity, here, refers to that which allows for a consciousness of the self through a turning back on the self. It is important to understand that the reflexive act is not exclusively volitional or intellectual, and that is can thus, paradoxically, be associated with automatic or pre-reflective processes. The act of thinking, of reflecting - about oneself, about one's experience, about the world - forms the base of one's narrative identity, and is thus included in this conception of reflexivity, but the latter cannot be reduced to a simple "act of thinking."
} 
It is difficult for the borderline patient to distance himself from his experiences; he is incapable of mediating them in a satisfactory manner. The borderline patient has a tendency to identify with each moment as it happens; she is completely immerged in each instant. The borderline relationship to space is marked by ubiquity [13], in the sense that "the now-experience and the person are one" ([12], p. 273). There is nothing separating the present moment and the self; present moment and self are "fused" together, and the person is "only what they are experiencing at the moment" ([9], p. 381). The safety margin that typically separates us from events is missing [12]. In consequence, many events take on an exaggerated importance for the patient. A perfect example can be found in borderline patients' characteristic interpersonal instability, due in part to the many "anodyne" events that are interpreted as veritable betrayals. Borderline patients have difficulty in distancing themselves from their immediate experiences and in adopting a meta position that could help them observe and analyze what is at stake in situations in which they feel themselves entangled, if not outright trapped.

For Meares [12,20], the fact the borderline patients experience such rapid mood swings is just one of the elements that corroborates the idea that they live in a kind of permanent present; that they are constantly absorbed by the thing itself, the immediate moment, the instantaneous emotion - and that second-order volitions don't sufficiently moderate these immediate experiences and motions. Meares also observes that interviews with borderline patients often consist of a "catalog of recent events" rarely accompanied by taking a step back to put things in perspective, as if these patients were incessantly caught up in the internal and external stimuli that they are unable to ignore.

In his work, Meares refers to a "traumatic (memory) system": instead of remembering events as memories, borderline patients seem to relive memories as if they were once again happening in the present. This phenomenon could also potentially explain the perceptual distortions and other pseudo-psychotic symptoms that occasionally occur. He attributes the pathogenesis of this "traumatic system" to an invalidating environment, and, more precisely, to a lack of recognition in interpersonal relationships that results in a lack of intimacy - in the sense of the feeling of being someone, of being oneself, based on a shared intimate experience with someone else. During the construction of the subject's identity, Meares argues, this complex hinders the development of an adequate "internal listener". When all goes well, this interior partner in dialogue, this interiorized and secure interlocutor, gives a concrete form to what Kimura calls aïda, by allowing for the emergence of the feeling of having an identity. And this thanks to the fact that the internal listener represents both a figure of alterity that implies that there is an other to talk to (the self, as a distinct entity, and thus endowed with an identity), and a figure of the fundamental intersubjectivity and collectivity that gives rise to the very concept of individuality.

\section{4. (Dis)embodied and emotional temporality}

Throughout this article, we have noticed just how central the oscillations and intensities of emotional experiences are to the borderline experience. It would seem useful, then, to clarify the phenomenological definition of an emotion. In phenomenology, emotions are, firstly, conceived of as "kinetic, dynamic forces that drive us in our ongoing interactions with the environment" ([12], p. 261). One could even suggest, as Sartre does [21], that an emotion is a condition sine qua non of the interactions between an individual and his environment.

The Latin roots of the word "emotion" (e-motio, e-movere) underscore the importance of movement. Likewise, emotional experiences are tendencies to action; they motivate and can bring about the production of movement. They are the organizers of our being-in-the-world; of our relationship to time, to space, to the self, and to others - in that they situate the person in 
the world, and "allow him to perceive the things that surround him as disclosing certain (and not other) possibilities" ([12], p. 262). Emotional experiences are also understood as "embodied intentionality" ([12], p. 262), since they form the basis of our attention and contribute to our feeling of being involved in the world, to our representations of things, to the meaning we find in them, and to our pre-reflective understanding of others' behavior. For all of these reasons (and because of the bodily sensations that they produce), emotions are understood as fundamentally corporeal $[22,23]$.

However, the fragmentation of time and of identity that we have explored in this article can also be found in the relationship to the body. Borderline patients often experience terrible difficulties in feeling like a person - this is a frequent reason for seeking therapy -, and many also report a feeling of distance from their own body, as if the body was "lying somewhere between self and non-self" ([12], p. 271), somewhere between self and other. Borderline patients can struggle to control their emotions; in the same way, they often speak of their body as being out of their control. All of the logical premises that found our judgment (the judgment that mediates our daily experience), such as the principles of identity, of non-contradiction, or of the excluded third, can be reduced to the principle of individuation: each person "has only one bodily life to live" ([8], p. 147), and each person is unique and self-contained. The absence of mediation - this missing "psychic force" $[9,12]$ that leads to a "chronic feeling of emptiness" - is intimately linked to the feeling that one's identity is vague at best and to the way that an individual experiences her own body. Here, we can think of borderline patients' frequent, spectacular acts of self-harm that regularly bring the bodily dimension into play. Many authors have pointed out that when these acts are not suicidal (e.g. cutting and self-inflicted burns), they resemble emotional regulation strategies that afford a certain relief, an experience of "discharge" [24]. The regulation of emotions through the bodily medium can take different forms, according to what they represent for each individual [24]: giving physical form to psychic pain [25]; punishing oneself or regulating one's dysphoria; communicating with one's entourage; remembering certain events by leaving a trace (a scar); or feeling more active (in the sense of being the agent of one's experiences, instead of experiencing them passively). In general, these actions on and by the body seem particularly relevant to our reflections on immediacy. We can, for example, imagine that the bodily medium "replaces" an insufficiently mediating reflective capacity. We could also posit a phenomenon of hypo-reflexivity - which, from a psychopathological point of view, could be opposed to schizophrenic hyper-reflexivity $[17,18,26,27]$. Lastly, we could note that if some patients claim not to experience any physical pain during these acts, others seem drawn to them precisely for this reason. We can think of physical pain as a substitute for a psychic pain that cannot be mediated [25]. The borderline patient's frequent attraction to tattoos can also be interpreted in light of these hypotheses ${ }^{3}$ [14]. Bringing the body into play is a paradoxical remedy, a means of overcoming the distress that characterizes a particular form of relationship between the body and the self.

\section{Conclusion: instantaneity and immediacy}

In this way, the two main definitions of the word "immediacy" reveal their continuity. Immediacy - in the sense of an absence of mediation, in the sense of a failure to behave in accordance with second-order volitions that allow for the evaluation and selection of different "first-order

\footnotetext{
${ }^{3}$ Englebert J, Follet V. "Du définitif au provisoire...": Psychopathologie et tatouage. In: Krtolica I, Feneuil A (Eds.), L'expérience de l'éternité. Paris: Hermann; 2018. In press.
} 
desires" - binds the borderline person to the present moment, to the immediate, following the second acceptation of the word. The borderline patient pursues a succession of desires and seems to completely and unquestioningly adapt to "each now" in a quasi-random way. If immediacy does, indeed, refer to something direct, it would be more precise to say that this notion reflects a kind of succession without links, without articulation. The immediate follows or precedes without a pause. There is scarcely any room for mediation in this way of relating to time, nor is there a place for an intermediary - whether in the form of a subject-agent of mediation or of the social environment, the latter being unable to take on the role of moderator, of intermediary in the personal experience of time.

Because of this deficit of mediation, the borderline subject possesses a certain flexibility. This subject, whom certain authors consider to be the standard-bearer (from a psychopathological point of view) of postmodernity's archetypal "(normally) flexible personality" [9], presents a pathology that could thus be considered a hyper-flexible syndrome, viewed through the lens of contemporary social tendencies, where an excess of mediation might induce existential consequences unlikely to help subjects better adapt or to contribute to their well-being. Indeed, this flexibility, rather than mediation, is perhaps a response to the postmodern societal evolution described above. And here, the hypothesis of an ambient hyper-adaptation present in borderline patients is perhaps less absurd than it might seem at first glance.

Instantaneity, as a "transcendental matrix of the postmodern human condition" ([11], p. 245), seems to have invaded the borderline subject's mode of existence. This devotion to the instantaneous represents the triumph of the fragment and of raw emotion, as well as the erasure of long-lasting social relationships, that one can observe in numerous phenomena, such as on social media. Bauman refers to our contemporary society as a "liquid" one [28,29], thereby differentiating it from modern, "solid" societies. Today, emotional and social phenomena seem less apt to allow the subject to forge a stable and well-defined identity for herself (whether implicitly or explicitly) - identity in the sense of the possibility of experiencing a subjectivity turned simultaneously towards a past made up of genuinely elaborated psychic experiences and towards a future made up of real projects. The human mind cannot match the pace of instantaneous daily life which has flourished thanks to incessant technological evolution - without falling into emptiness and existential suffering. Logically, then, the borderline person would be the "hyperbole" of an era characterized by fragmentation $[10,11]$ - an offspring, or the shrapnel, of postmodernity ${ }^{4}$ $[13,14]$ - and, in this sense, perfectly adapted to this regime.

As a final observation, we might remark that the concepts of immediacy and instantaneousness deal with the same phenomenon but consider different aspects of it. The focus on the medium reveals a relational logic (the relation of the borderline individual to time and to others) and suggests a more "spatial" problematization of lived time (the place of the subjects and of others in the process). Focusing on the dimension of the instant introduces, instead, a narrative and intrapsychic problematic in the subject's relationships to past, present, and future, and allows for the development of a more "temporal" argument concerning an intimate lived experience of time.

\section{Disclosure of interest}

The authors declare that they have no competing interest.

\footnotetext{
${ }^{4}$ Englebert J, Follet V. "Du définitif au provisoire. ..": Psychopathologie et tatouage. In: Krtolica I, Feneuil A (Eds.), L'expérience de l'éternité. Paris: Hermann; 2018. In press.
} 


\section{References}

[1] American Psychiatric Association. DSM-IV-TR : manuel diagnostique et statistique des troubles mentaux. $4^{\mathrm{e}}$ édition rev Paris: Masson; 2003 [Trad. Fr. JD Guelfi et MA Crocq].

[2] American Psychiatric Association. DSM-5 : manuel diagnostique et statistique des troubles mentaux. $5^{\mathrm{e}}$ édition Paris: Masson; 2016 [Traduit fr. JD Guelfi et MA Crocq].

[3] Livesley WJ. Handbook of personality disorders: theory, research and treatment. New York: Guilford Press; 2001.

[4] Widiger TA. The Oxford handbook of personality disorders. Oxford: Oxford University Press; 2012.

[5] Desseilles M, Grosjean B, Perroud N. Manuel du borderline. Paris: Eyrolles; 2014.

[6] Stanghellini G. Psicopatologia del senso comune. Milan: Cortina; 2006.

[7] Englebert J. Psychopathologie de l'homme en situation. Paris: Hermann; 2013.

[8] Kimura B. Écrits de psychopathologie phénoménologique. Vendôme: Presses Universitaires de France; 1992.

[9] Fuchs T. Fragmented selves: temporality and identity in borderline personality disorder. Psychopathology 2007;40(6):379-87.

[10] Muscelli C, Stanghellini G. Istantaneità: cultura e psicopatologia della temporalità contamporanea. Milan: FrancoAngeli; 2012.

[11] Muscelli C, Stanghellini G. La vulnerabilità ai tempi dell'istantaneità: il presente e la condizione borderline. Psicoterapia e scienze umane 2014;48(2):254-66.

[12] Stanghellini G, Rosfort R. Emotions and personhood: exploring fragility-making sense of vulnerability. Oxford: Oxford University Press; 2013.

[13] Englebert J. Ubiquité et situation : pour une considération topologique de la limite. Le Cercle Herméneutique; 2017. p. 28-9 [107-113].

[14] Englebert J, Follet V. Personnalité borderline et tatouage : hippolyte et le corps-en-disparition. Cah Psychol Clin 2018;50(1):231-48.

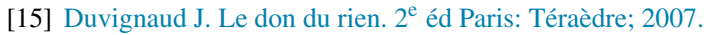

[16] Frankfurt HG. Freedom of the will and the concept of a person. J Philos 1971;68(1):5-20.

[17] Sass LA. Madness and modernism: insanity in the light of modern art, literature and thought (1992). Oxford: Oxford University Press; 2017 [Nouv ed rev].

[18] Sass LA. Les paradoxes de la réflexivité. In: Englebert G, Corman G, editors. Psychopathologie et philosophie: nouveaux débats et enjeux contemporains. Paris: Le Cercle Herméneutique; 2016. p. 185-219.

[19] Bauman Z. S'acheter une vie. Chambon: Le Rouergue; 2008.

[20] Meares R. Intimacy \& alienation: memory, trauma and personal being. New York: Routledge; 2000.

[21] Sartre JP. Esquisse d'une théorie des émotions. Paris: Hermann; 1939.

[22] Gallagher S. How the body shapes the mind. Cambridge: Oxford University Press; 2005.

[23] Gallagher S, Zahavi D. The phenomenological mind: an introduction to philosophy of mind and cognitive science. London: Routledge; 2008.

[24] Monti MR, D’Agostino A. Abnormal bodily experience in borderline personality disorder: clinical issues and psychopathological perspectives. Clin Neuropsychiatry 2016;13(3):37-42.

[25] Pirlot G, Cupa D. La douleur peut-elle être perçue et cherchée plus « vivement » dans une culture postmoderne en perte de sens ? Evol Psychiatr 2006;71(4):729-43.

[26] Englebert J, Valentiny C. Schizophrénie, conscience de soi, intersubjectivité : essai de psychopathologie phénoménologique en première personne. Bruxelles: De Boeck; 2017.

[27] Englebert J, Stanghellini G, Valentiny C, Follet V, Fuchs T, Sass L. Hyper-réflexivité et perspective en première personne : un apport décisif de la psychopathologie phénoménologique contemporaine à la compréhension de la schizophrénie. Evol Psychiatr 2018;83(1):77-85.

[28] Bauman Z. La vie liquide. Chambon: Le Rouergue; 2002.

[29] Bauman Z. Culture in a liquid modern world. Cambridge: Polity; 2011. 